\title{
Cross Compliance GAEC standards implemented in Italy: environmental effectiveness and strategic perspectives
}

\author{
Paolo Bazzoffi, ${ }^{1}$ Camillo Zaccarini Bonelli² \\ ${ }^{1}$ Agricultural Research Council, CRA-ABP Agrobiology and Pedology Research Centre, Florence; \\ ${ }^{2}$ Institute of Services for Agricultural and Food Markets (ISMEA), Coordinator of the Italian \\ National Rural Network, Rome, Italy
}

\section{Context}

The debate on the future of the Common Agricultural Policy (CAP), which is growing at European and National level, is notably and closely linked to the choices of EU related to the financial perspectives for the period 2014-2010.

A public consultation on such topic has been started off by the EU Agriculture Commissioner Dacian Cioloş, who has left for the moment the two dossiers aside, giving priority to the identification of the agricultural policy post-2013 objectives.

The debate on the new CAP reform, starting from the always ancient but modern general objectives which remained unchanged with the Lisbon Treaty, is now subject to an in-depth analysis and revision to identify new specific objectives in the wider framework of the European strategy 2010 identified by the EU executive body.

However, the future outlooks can not neglect the need for stocktaking and what has been learned through the present and recent past experiences.

In order to focus the theme of this special issue of the Italian Journal of Agronomy, we must remember that on $26^{\text {th }}$ June 2003, EU farm ministers adopted a fundamental reform of the CAP and introduced a new single payment scheme (SPS, or Single Farm Payment) intended to change the way the EU supported its farm sector by removing the link between subsidies and production of specific crops. The Single Farm Payment is linked to meeting environmental, public, animal and plant health and animal welfare standards and the need to keep land in good agricultural and environmental condition. To gain funds from the SPS the Farmer has to cross comply - that is, to farm in an environmentally friendly way.

COUNCIL REGULATION (EC) No 1782/2003 states that: Member States shall define, at national or regional level, minimum requirements

\footnotetext{
Correspondence: Paolo Bazzoffi, Agricultural Research Council, CRA-ABP Agrobiology and Pedology Research Centre, Florence, Italy.

E-mail: paolo.bazzoffi@entecra.it

Received for publication: 28 January 2010

Accepted for publication: 10 May 2010.

(C) Copyright P. Bazzoffi and C. Zaccarini Bonelli, 2011

Under no circumstances figures can be used without prior written consent of the copyright owner.

Licensee PAGEPress, Italy

Italian Journal of Agronomy 2011; 6(s1):e1

doi:10.4081/ija.2011.6.s1.e1
}

This work is licensed under a Creative Commons Attribution NonCommercial 3.0 License (CC BY-NC 3.0). for good agricultural and environmental condition on the basis of the framework set up in Annex IV, taking into account the specific characteristics of the areas concerned, including soil and climatic condition, existing farming systems, land use, crop rotation, farming practices, and farm structures.

GAECs (cross compliance Standards of Good Agricultural and Environmental Condition) form part of the minimum requirements and set statutory management requirements for farmers as referred to in annex IV (Table 1) of the EC REG. 1782/03 in respect of soils, as well as maintaining a range of habitat and landscape features.

The cross compliance acknowledgement process and its implementation in Italy took place through the first Ministerial Decrees, considered the result of an in-depth examination carried out by the Ministry of Agriculture through technical discussion with the Regions and the Autonomous Provinces, and with the socio-economic and environmental partnership, up to the technical definition of the GAECs.

The effectiveness of such criteria needed be proved and recognized by the agronomical science and, at the same time, complying with GAECs should not be more onerous compared to the common agricultural activities standards.

The introduction of cross compliance, besides the decoupling of aids in the framework of the first pillar, represents one of the main aspects of the CAP and needs special attention.

The analysis of Feoga (European Agricultural Guidance\& Guarantee Fund) shows that in the period 2007 - 2009 France was the largest beneficiary of the EU funds for the first Pillar of CAP with 8.7 billion euro (equal to $21 \%$ of the total), followed by Spain (more than 5.7 million euro, equivalent to $14 \%$ ) and Germany (5.4 billion equal to $13.3 \%$ ). In fourth place Italy, which received funding for about 11 per cent of the total (4.5 billion euro), followed by England ( 8 per cent).

Considering this relevant amount of money spent for the first Pillar it appears evident the necessity to verify the effectiveness of cross compliance in order to justify this European policy in the eyes of the citizen.

Indeed, EU legislation does not provide the measurement and evaluation of results obtained by cross compliance. This aspect is a limit for a policy that represents the main pillar of the CAP in the production of public goods and that should be periodically verified.

Monitoring of cross compliance should be consistent and coordinated with the common monitoring and evaluation framework, which is already in use for rural development, by establishing concrete and quantified goals in a systematic way for its integration.

Cross compliance brought to the CAP and to the rural development policies new objectives and purposes but also new rules for farmers to comply with.

The development path, started in the wake of the Fischler Reform and aimed at accompanying and mitigating probable decoupling impacts, has been playing day by day an always more important role. Such key role has been also confirmed by the recent Health Check reform, which pointed out the new environmental challenges also pur- 
sued by the cross compliance standards.

In case of non-respect of such standards, the farmer is subject to a reduction of the EU aids that have been asked for as direct payments or RDPs axis 2 measures. Such reduction, which can lead to the total exclusion in extreme cases, is proportional to the seriousness, the extent and persistence of the adverse effects coming from the nonrespect of cross compliance requirements.

Cross compliance is a complex system of rules which has implied and implies a continuous update and adjustment effort to be carried out by both public stakeholders involved in the cross compliance acknowledgement and implementation and by farmers which are the direct addressee of such policy.

The European Court of Auditors, in the Special Report No 8/2008 - Is cross-compliance an effective policy? points out the limits of the system introduced through the 2003 CAP reform, already gradually introduced into some instruments starting from Agenda 2000.

The analysis carried out in Italy by Institute of Services for Agricultural and Food Markets (ISMEA) in the framework of the National Rural Network (NRN) activities and relating to the first period of cross compliance implementation - from its introduction in 2005 up to 2009 -, is trying to give a new answer to such a question, which has been replied to also by the European Commission. For this purpose and cconsidering the importance of assessing the GAECs impact on the agricultural and environmental system the NRN-ISMEA started in 2009 the collaboration between the Ministry of Agricultural, Food and Forestry Policies (MiPAAF), the Agricultural Research Council (CRA), AGEA (Italian Agency for Agricultural Payments) and SIAN (Agricultural Information System) in order to evaluate, together with many other aspects of the implementation of cross compliance in Italy, the environmental effectiveness of the GAEC Standards, through the preliminary experimental results of case studies. When needed, new agronomic practices have been proposed to improve the effectiveness of the standards. Some of them can be added to the actual GAEC standards, others can be added to the existing agri-environmental measures.

The scientific results are provided for by the Agricultural Research Council (CRA) through the findings of experiments carried out by the EFFICOND project (described in the next chapter) or data collected from other national researches, carried out in the past, in which the experimental design included the evaluation of the environmental effect of treatments similar to those of the GAECs standards (Ex. experiments on the effect of set aside on soil erosion).

This Special Issue of the Italian Journal of Agronomy collects the papers produced by the scientific community who participated to the EFFICOND Project.
This intense process of research, selection, collection, and harmonization of the data coming from the Italian scientific literature on agriculture is also shown in synthesis in the Report titled Cross Compliance Implementation In Italy (in Italian, available from http:/www.reterurale.it/flex/cm/pages/ServeBLOB.php/L/IT/IDPagina/3984), drawn up by the National Rural Network 2007/2013 - ISMEA and presented at the GAEC workshop (Rome, 6-8 October 2010).

The evaluation results are presented in the report as answers to precise questions phrased within the NRN-ISMEA working group in order to address the questions, which can be formulated on the basis of the issues and standards of annex IV of Council Reg. No 1782/2003.

The questions are:

Issue 1. Protection of soil from erosion through appropriate practices

Question 1.1: To what extent do temporary drainage ditches across the slope and grass strips exert positive contribution to the protection of soil against erosion? Standard 1.1

Question 1.2: To what extent do retention of stonewall terraces and earth terraces exert a positive contribution to the protection of soil against erosion? Standard 4.4a

Question 1.3: To what extent do prohibition of land leveling without permission exert a positive contribution to the protection of soil against erosion? Standard 4.4b

Question 1.4: To what extent do ensuring the presence of grass cover throughout the year on set aside exert a positive contribution to the protection of soil against erosion? Standard 4.2a

Issue 2. Maintain soil organic matter levels through appropriate practices Question 2.1: to what extent do management of stubble and crop residues exert a positive contribution to maintenance of levels of soil organic matter? Standard 2.1

Question 2.2: To what extent do crop rotations exert a positive contribution to maintenance of levels of soil organic matter? Standard 2.2

Issue 3. Maintain soil structure through appropriate practices

Question 3.1: To what extent do ploughing in good soil moisture condition avoid the decay of soil structure? Standard 3.1b

Question 3.2: To what extent do maintenance in good efficiency of the farm network of permanent channels avoid the decay of soil structure? Standard 3.1a

Issue 4. Ensure a minimum level of maintenance of ecosystems and avoid the deterioration of habitats

Question 4.1: To what extent do prohibition to reduce the area of pasture or convert pasture to other uses avoid the deterioration of habitats? Standard 4.1a and b

Question 4.2: To what extent do optimal livestock Units per ha. (Min.0.2

Table 1. Annex IV of COUNCIL REGULATION (EC) No 1782/2003 on Good Agricultural and Environmental Condition.

Issue Standards

Soil erosion

Protect soil through appropriate measures

Minimum soil cover

Minimum land management reflecting site-specific conditions Retain terraces

Soil organic matter

Maintain soil organic matter levels through appropriate practices

Soil structure

Maintain soil structure through appropriate measures

Minimum level of maintenance

Ensure a minimum level of maintenance and avoid the deterioration of habitats
Standards for crop rotations where applicable Arable stubble management

Appropriate machinery use

Minimum livestock stocking rates or/and appropriate regimes

Protection of permanent pasture

Retention of landscape features

Avoiding the encroachment of unwanted vegetation on agricultural land 
Table 2. Standards effectiveness (Italian National Rural Network 2010, evaluated by the EFFICOND (CRA- Agricultural Research Council) project (from the Report on cross compliance implementation in Italy).

\begin{tabular}{|c|c|c|c|c|c|}
\hline \multicolumn{6}{|c|}{ Implementation of regulation before the Health Check } \\
\hline \multicolumn{6}{|c|}{ Effectiveness of Standards vs. Issues } \\
\hline & GAEC Standards & $\begin{array}{l}\text { Issue } 1 \\
\text { Soil } \\
\text { erosion }\end{array}$ & $\begin{array}{l}\text { Issue } 2 \\
\text { Soil organic } \\
\text { matter }\end{array}$ & $\begin{array}{l}\text { Issue } 3 \\
\text { Soil } \\
\text { structure }\end{array}$ & $\begin{array}{l}\text { Issue } 4 \\
\text { Minimum } \\
\text { of level } \\
\text { of habitat } \\
\text { mainte- } \\
\text { nance }\end{array}$ \\
\hline Standard 1.1 & $\begin{array}{l}\text { Temporary runoff control measures in sloping land (temporary } \\
\text { drainage ditches across the slope or alternate grass strips) }\end{array}$ & High & & & \\
\hline Standard 3.1a & $\begin{array}{l}\text { Protection of soil structure through efficient drainage of surface } \\
\text { water. (Shaping the surface of fields convex to avoid waterlog- } \\
\text { ging. Maintenance in good efficiency of the farm network of per- } \\
\text { manent channels), letter a }\end{array}$ & & & High & \\
\hline Standard 4.4b & $\begin{array}{l}\text { Retention of characteristic landscape features } \\
\text { (Retain stonewall terraces and earth terraces. } \\
\text { Prohibition of unauthorized land levelling), letter b }\end{array}$ & Low & & & Low \\
\hline Standard 4.2a & $\begin{array}{l}\text { Rational management of Set-aside } \\
\text { (Ensure the presence of grass cover throughout } \\
\text { the year on set aside) letter a }\end{array}$ & High & & & High \\
\hline Standard 4.4a & $\begin{array}{l}\text { Retention of characteristic landscape features } \\
\text { (Retain stonewall terraces and earth terraces), letter a }\end{array}$ & High & & & High \\
\hline Standard 2.1 & $\begin{array}{l}\text { Management of stubble and crop residues } \\
\text { (Prohibition of burning of stubble and crop residues) }\end{array}$ & & Low & & \\
\hline Standard 2.2 & Crop rotation & & Low & & \\
\hline Standard 3.1b & $\begin{array}{l}\text { Soil structure protection through appropriate machinery use } \\
\text { (Ploughing in good soil moisture condition), letter b }\end{array}$ & & & High & \\
\hline Standard 4.1a, b & $\begin{array}{l}\text { Protection of permanent pasture } \\
\text { (Prohibition to reduce the area of pasture), letter a } \\
\text { (Prohibition to convert pasture to other land use), letter b }\end{array}$ & & & & High \\
\hline Standard 4.1c & $\begin{array}{l}\text { Protection of permanent pasture } \\
\text { (Optimal livestock Units per ha. Min. and Max. values allowed), } \\
\text { letter c }\end{array}$ & & & & High \\
\hline Standard 4.2b & $\begin{array}{l}\text { Rational management of Set-aside } \\
\text { (Weed control through mowing), letter b }\end{array}$ & & & & Low \\
\hline Standard 4.3b & $\begin{array}{l}\text { Maintenance of olive groves in good vegetative condition } \\
\text { (Frequency of pruning. Frequency of cleaning the } \\
\text { soil from brambles and shrubs), letter b }\end{array}$ & & & & High \\
\hline Standard 4.4c, d & $\begin{array}{l}\text { Retention of characteristic landscape features } \\
\text { (landscape protection) letters c-d }\end{array}$ & & & & High \\
\hline
\end{tabular}


and Max.4) avoid the deterioration of habitats? Standard 4.1c

Question 4.3: To what extent do weed control on set aside avoid the deterioration of habitats? Standard 4.2b

Question 4.4: To what extent do maintenance of olive plants in good vegetative condition avoid the deterioration of habitats and land abandonment? Standard 4.3a

Question 4.5: To what extent do retention of characteristic landscape features (stone-wall terraces and earth terraces) avoid the deterioration of habitats? Standard $4.4 \mathrm{c}$

The answers given to the questions are grouped by GAECs environmental objectives (issues) in order to ensure a coherent and logical text comprehension, thus strengthening the integration of cross compliance requirements with the rural development objectives and measure as well as focusing the attention on the standards that most integrate with the objective itself. Table 2 shows, in summary, the effectiveness of standards in relation to environmental objectives.

The results achieved reveal how cross compliance policy plays a key role, which cannot be replaced, in the present and future CAP framework.

The report and the scientific papers of this special issue, describe also, for each group of standards related to the same objective, observations and prescriptions aimed at better identifying cross compliance obligations that could integrate the need for farmers to better comply with minimal agricultural obligation with the environmental protection effectiveness required by the CAP.

The report confirms the progressive entry into force of such an instrument which also shows interesting effects for achieving the objectives set out by the Community rules and, in particular, for a sustainable management of agricultural land and food safety. The report analyses the relevant regulatory framework, describing the development process of cross compliance policy standards. From Agenda 2000 to the Fischler Reform, a gradual integration of environmental objectives in the market and rural development policies framework has occurred, thus leading to the set-up of Good Agricultural and Environmental Conditions (GAECs) and Statutory Management Requirements (SMRs) not only in terms of environmental policies but also in food safety, animal welfare and health and plant health.

\section{The EFFICOND Project}

EFFICOND (EFF, Effectiveness of environmental standards and COND, Cross compliance) is an Agricultural Research Council (CRA) project started in 2009 to meet the specific need of National Rural Network (NRN) to monitor and evaluate the effectiveness of environmental protection actions mandated by the CAP to national agricultural policy and implemented by the Regional Rural Development Plans (RDP). The main project objectives are the evaluation of GAEC standards implemented under cross compliance and the development of agri-environmental indicators for nation-wide scenario analysis. The EFFICOND project involves 10 operational units with experimental fields located throughout the country.

This resulted in a significant scientific relapse, in terms of acquisition of new knowledge and about the effects of GAEC Standards applied in different environments.

The Research Centres were selected (among all the Research Centres of CRA) on the basis of scientific skill on GAEC Standards. They result well distributed on the national territory and represent different environments. Many Research Centres have two or three experimental farms located in different provinces.

The location of the Research Centres of CRA that participate to the EFFICOND project is shown in Figure 1.

To evaluate the GAEC standards three project objectives have been identified:

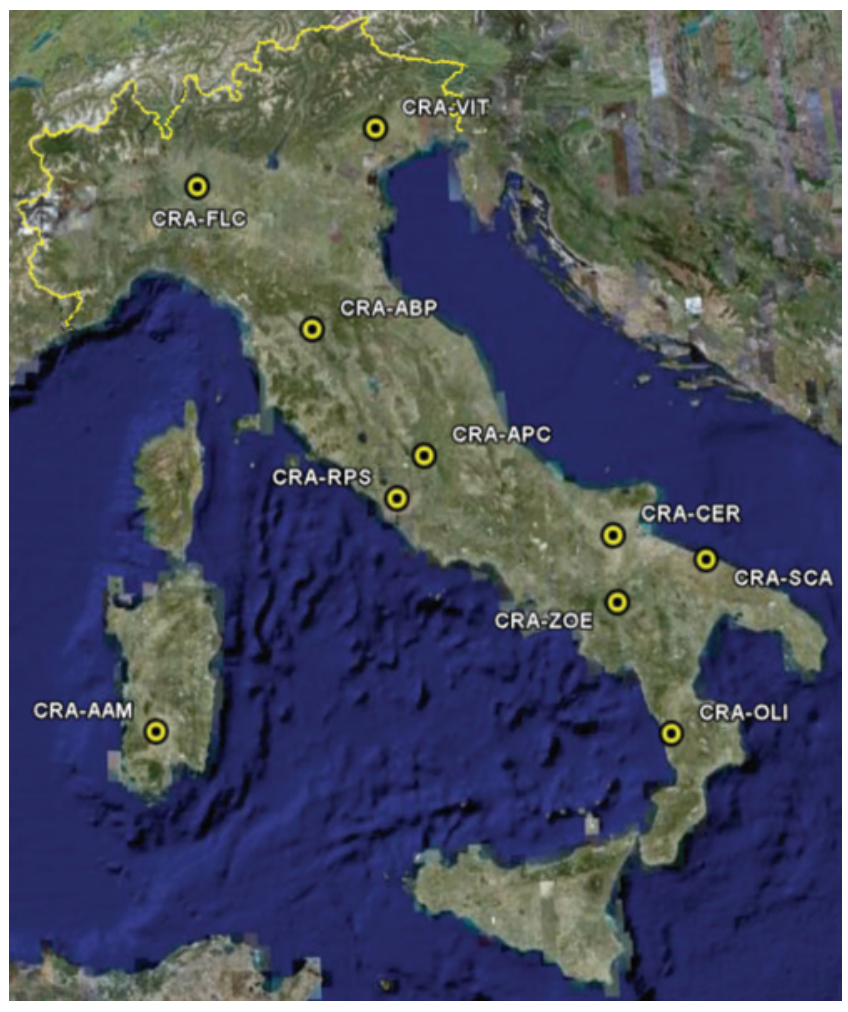

Figure 1. Location of the Research Centres of CRA participating to the EFFICOND project.

i) Determine the adequacy of GAEC Standards to mitigate the environmental threats resulting from the agricultural land use

ii) Produce indicators to be integrated in the Agency for Payments in Agriculture (AGEA) GIS system to provide quantitative nation-wide answers to the European Commission.

iii) Transfer the scientific information acquired to MiPAAF and Regions in order to refine and simplify the Standards in future Ministerial Decrees.

The support given by Institute of Services for Agricultural and Food Markets (ISMEA) to the project is very noticeable. This institution is the holder of the Task Force Environment and Cross Compliance of NRN and provided essential information to the formulation of this project. Furthermore ISMEA-NRN guided and harmonized the collaboration of the project with the action of other Institutions as the NRN, MiPAAF, AGEA and National Agricultural Information System (SIAN).

In particular, the EFFICOND project aims at providing appropriate instruments to tailor the commitments to achieve the Good Agronomic and Environmental Conditions, by making these commitments as possible contextualized in the reality of the specific farm, even though the assistance provided to farmers on the basis of scientific knowledge resulting from the project.

As known, the guiding principle of cross compliance is to harmonize the need to impose minimal agronomic commitments, feasible by farmers at minimal costs, with the achievement of minimum goals of environmental sustainability in order to avoid the application of the polluterpay principle (reduction of the Single Farm Payment).

GEAC standards just aims to reduce the environmental threats within the tolerance thresholds, without producing more goods and services that go beyond the minimum requirements. In fact, the production of more goods and services (improvement of the environmental functions) is a goal of the second pillar of the CAP, implemented in the RDP in the form of voluntary agri-environmental measures. Therefore, researchers 
who have contributed to the EFFICOND project, adhering to these principles, proposed (when needed) a modification to the GAEC standards in order to get the most out of positive externalities through small additional commitments.

In some cases, it was suggested a drastic simplification (non-application of the standard) when it was recognized that it is ineffective in relation to the particular soil conditions.

The EFFICOND project is the first step toward the establishment of a national network of research centres and experimental farms for the continuous monitoring of the effectiveness of GAEC and agri-environmental measures.

\section{Strategic objectives related to Cross Compliance GAEC standards}

It is important underlining that, for the first time in Italy, in the implementation of the first pillar of the CAP, direct payments could be related to territorial aspects, while in the past their importance was related only to Structural Funds and rural development interventions. Together with this vertical integration, cross compliance implementation led to a new horizontal cooperation aspect between the public competent authorities as to Agriculture and those authorities in charge of the other cross compliance areas (Public Health, Environment).

The national importance of the strategic objectives related to cross compliance cannot be fully understood if not considering the main agriculture and environmental critical issues at national level that GAECs and SMRs are trying to cope with. Identifying the basis of the strategic objectives connected with the cross compliance obligations, means reshaping, in the interests of complementarity, a unitary framework thanks to the Rural Development National Strategic Plan (NSP) key actions and to RDPs 2007-2013 measures.

The critical issues to be taken into account harming soil integrity and functionality refer to soil erosion, organic matter decline, soil compaction, but also to ensure the minimum level of ecosystem maintenance and avoid habitats and landscape deterioration.

Starting from this context, the synergy between cross compliance and the rural development strategy - the second pillar of the CAP - plays a new role, also with a view to post 2013. Such synergy, as a complement to the Common Agricultural Policy, is accompanying and integrating the interventions provided for by the market and income support policies.

It follows an articulated intervention framework that highlights coherence and complementarity between cross compliance and the agrienvironmental actions, thanks to the analysis of the logical connections among Italian territory main critical issues on which cross compliance policy fields and objectives are focused, through their respective statutory requirements and RDPs measures.

During the first years of cross compliance implementation, important observations have been carried out; such observations can help future choices to be undertaken at national and international level, within the post 2013 CAP debate.

The following four points are considered of particular importance: i) giving cross compliance a strategic approach; improving the first and second pillar integration and complementarity, emphasizing the link with the public goods; ii) enhancing cross compliance effectiveness and verifiability; setting up concrete and quantified objectives; strengthening the integration with the monitoring and evaluating system already provided for by the rural development; iii) reducing the number of standards and obligations coherently with the standards simplification process; fostering a systemic approach that, from one hand, allows to move from one objective-one standard structure towards a multi-objective approach and, from the other hand, contributes to set up a single regulatory framework coherent with the provisions related to spatial planning; iv) strengthening the role played by farm advisory services supporting farmers to meet cross compliance requirements.

The first point aims at giving cross compliance a strategic approach: in the current programming period, although the evident relations between the first and the second pillar as regards the cross compliance policy, this relations are prevalently related to bureaucratic aspects (assessments, advisory services), while a unitary and strategic approach is needed.

The above mentioned cross compliance Report reveals the autonomous character of cross compliance objectives within the direct payments regulation, while RDPs objectives come from a Community, national and regional strategic framework often independent also as regards those objectives that fit exactly with the cross compliance objectives.

It is therefore necessary to enhance the integration of cross compliance first and second pillar into a single strategic framework, emphasizing the link with public goods that seems to be the bridge between market policies and rural development policies purposes.

Particularly important is to enhance cross compliance verifiability and effectiveness, setting up concrete and quantified objectives aimed at strengthening the integration with the monitoring and evaluating system already provided for by the rural development, thus preventing the bureaucratic burden.

Coherently with the standards simplification process and the reform of the second pillar of the CAP, a systemic approach is needed to identify and implement the minimum GAECs standards that farmers must comply with in order to be eligible for the public aid, thus moving from one objective-one standard structure towards a multi-objective approach.

As demonstrated by the scientific results, the same standard can contribute to reach different environmental objectives/priorities. According to this approach, the standards mix should be identified at territorial and/or farm level in order to i) ensure that all the objectives to be reached in function of the farm and of the territory are met, ii) act coherently with the standards simplification procedures, setting up the standards according to the needs of the single farm/territorial context and get rid of the unnecessary/not functional standards.

It is worth underlining the important contribution given by the cross compliance policy to the new strategic challenge on climatic changes; such challenge, being at wide range, needs for a coordinated intervention between the first and the second pillar of the CAP.

In conclusion, the role played by farm advisory services needs to be strengthened. For this reason, as a priority action, a farm check-up should be applied and a specific financing system in the pillar of the CAP should be implemented in areas with a higher environmental risk or a fragile agro-ecosystem, as well as for standards particularly complex to comply with or characterised by a potential low effectiveness level due to the lack of a highly qualified support.

\section{References}

European Commission, 2010. The CAP towards 2020: Meeting the food, natural resources and territorial challenges of the future. $\operatorname{COM}(2010)$ 672/final. Available from: http://ec.europa.eu/agriculture/cap-post-2013/communication/com2010-672_en.pdf

European Court of Auditors, 2008. Is cross compliance an effective policy?. Special Report No 8/2008. Available from: http://eca.europa.eu/ portal/pls/portal/docs/1/2246310.PDF

Rural Development National Strategic Plan 2007/2013, 21 June 2010. Available from: http://www.reterurale.it/flex/cm/pages/Serve BLOB.php/L/IT/IDPagina/3469

Italian National Rural Network, 2010. Report on cross compliance implementation in Italy. Available from: http//www.reterurale.it/flex/cm/ pages/ServeBLOB.php/L/TT/IDPagina/3984. 